\title{
A deterministic simulation study of embryo marker-assisted selection for age at first calving in Nellore (Bos indicus) beef cattle
}

\author{
Artur J.M. Rosa ${ }^{1}$, Piter Bijma ${ }^{2}$, Henrique N. Oliveira ${ }^{3}$, Raysildo B. Lôbo ${ }^{4}$ and Johan A.M. van Arendonk ${ }^{2}$ \\ ${ }^{1}$ Department of Entomology, Phytopathology, Microbiology, Agriculture and Animal Science, \\ University of Palermo, Italy. \\ ${ }^{2}$ Animal Breeding and Genetics Group, Wageningen University, Wageningen, The Netherlands. \\ ${ }^{3}$ Departamento de Melhoramento e Nutrição Animal, Faculdade de Medicina Veterinária, \\ Universidade Estadual Paulista, Botucatu, SP, Brazil. \\ ${ }^{4}$ Departamento de Genética, Faculdade de Medicina de Ribeirão Preto, Universidade de São Paulo, \\ Ribeirão Preto, SP, Brazil.
}

\begin{abstract}
We used deterministic simulation of four alternative multiple ovulation and embryo manipulation (MOET) closed nucleus schemes to investigate the benefits of using marker-assisted selection (MAS) of Nellore (Bos indicus) beef cattle embryos prior to transplantation to reduce the age at first calving (AFC). We found that MAS resulted in increased genetic gain as compared to selection without AFC quantitative trait loci (AFC-QTL) information. With single-stage selection the genetic response (GR) increased as follows: GR $=0.68 \%$ when the AFC-QTL explained 0.02 of the AFC additive genetic variance $\left(\sigma_{A}^{2}\right)$; GR $=1.76 \%$ for AFC-QTL explaining $0.05 \sigma_{A}^{2}$; GR $=3.7 \%$ for AFC-QTL explaining $0.1 \sigma_{A}^{2}$; and GR $=55.76 \%$ for AFC-QTL explaining $0.95 \sigma_{A}^{2}$. At the same total selected proportion, two-stage selection resulted in less genetic gain than single stage MAS at two-years of age. A single stage selection responses of $\geq 95 \%$ occurred with pre-selected proportions of $0.4\left(0.1 \sigma_{A}^{2}\right.$ explained by AFC-QTL), $0.2\left(0.3 \sigma_{A}^{2}\right.$ explained by AFC-QTL) and $0.1\left(0.5 \sigma_{A}^{2}\right.$ explained by AFC-QTL), indicating that the combined use of MAS and pre-selection can substantially reduce the cost of keeping recipient heifers in MOET breeding schemes. When the number of recipients was kept constant, the benefit of increasing embryo production was greater for the QTL explaining a higher proportion of the additive genetic variance. However this advantage had a diminishing return especially for QTL explaining a small proportion of the additive genetic variance. Thus, marker assisted selection of embryos can be used to achieve increased genetic gain or a similar genetic response at reduced expense by decreasing the number of recipient cows and number of offspring raised to two-years of age.
\end{abstract}

Key words: age at first calving, beef cattle, marker-assisted selection, pre-selection, quantitative trait loci.

Received: September 21, 2006; Accepted: April 2, 2007.

\section{Introduction}

A major reproductive trait in beef cattle is age at first calving (AFC), which is related to sexual precocity and measures the time from the birth of a heifer to its first calving. A lower AFC has a positive impact on both economic and breeding aspects of cattle production, such as reduced costs of raising heifers and reduced female generation interval. Despite the importance of AFC, many breeding programs do not include this trait in the breeding goal because of its low heritability, sex-limited expression and antago-

Send correspondence to Artur J.M. Rosa. Department of Entomology, Phytopathology, Microbiology, Agriculture and Animal Science, University of Palermo, 90128 Palermo, Italy. E-mail: artur. rosa@unipa.it. nistic relationships with production traits (Frazier et al., 1999; Nogueira, 2004, Forni and Albuquerque, 2005; Pereira et al., 2006).

In recent years, dense genetic maps of DNA markers have become available for several species, including cattle (Barendse et al., 1997; Bishop et al., 1994). In livestock, the major goal of map construction is to dissect the genome to identify genes or chromosomal regions controlling the expression of economically important traits, often called quantitative trait loci (QTL). Numerous experiments have been conducted to detect QTL with promising results for several species, including milk yield and composition, disease resistance, reproduction, growth and carcass traits in beef and dairy cattle (Weller et al., 1990; Van Der Beek et al., 1995; Schrooten and Bovenhuis, 2002, Casas et al., 
2004, Gonda et al., 2004, Schnabel et al., 2005, Stone et al., 2005, Mizoguchi et al., 2006).

Breeding programs which use marker assisted selection (MAS) can use information on QTL to improve the accuracy of early selection in, for example, heifers or embryos. Marker assisted selection can help to increase genetic response, especially for traits with low heritable, sexlimited traits and late or postmortem measurable traits (Lande and Thompson, 1990; Meuwissen and Van Arendonk, 1992; Brascamp et al., 1993; Ruane and Coleau, 1996; Meuwissen and Goddard, 1996; Spelman et al., 1999; Spelman and Bovenhuis, 1998; Mackinnon and Georges, 1998; Meuwissen et al., 2001; Dekkers and Hospital, 2002, Williams, 2005, Powel and Norman, 2006, Spotter and Dist, 2006).

Advances in DNA technologies have also favored the development of several reproductive technologies, such as embryo transfer (ET), ovary pick-up (OPU), in vitro fertilization (IVF), in vitro production of oocytes derived from stem cells and cryopreservation. These techniques can be used to increase the number of embryos produced per cow and consequently the number of animals available for selection. Another research area of interest in embryo technology is the development of preimplantation genetic typing, also called preimplantation genetic diagnosis (PGD), which livestock breeders can use to predict phenotypic characteristics such as gender and production performance prior to embryo transfer and prevent transmission of genetic disorders. Preimplantation genetic diagnosis can be performed using single cells from biopsies and polymerase chain reaction (PCR) or fluorescent in situ hybridization (FISH) to determine gender or the presence of desired alleles in half-sib or full-sib embryos (Gomez-Raya and Klemetsdal, 1999, Bredbacka, 2001, Chrenek et al., 2001, Abdel-Azim and Freeman, 2002, Stella et al., 2002, Virta et al., 2002, Hirayama et al., 2004, Hansen and Block, 2004, Lee et al. 2004, Basrur and King, 2005, Mapletoft and Hasler, 2005, Hageyama et al. 2006).

There are various reports of livestock pregnancy rates of $30 \%$ to $60 \%$ when using biopsied embryos, similar to the rates obtained with intact embryos and considered sufficient for commercial applications (Agca et al., 1998, Chrenek et al. 2001, Garcia, 2001, Lopes et al. 2001, Park et al. 2001, Chen et al. 2002, Tominaga, 2004, Tominaga and Hamada, 2004).

A multistage selection procedure that combines the favorable aspects of independent culling and index selection has been presented by Xu and Muir (1991). A multistage selection program can be optimized to maximize aggregated economic gain and incorporate genetic marker information, but the main advantage of multistage selection procedures over single-stage selection procedures is costsaving (Xu et al., 1995, Schulman and Dentine, 2005, Schrooten et al., 2005). Multistage selection and marker assisted selection can be combined with preimplantation ge- netic diagnosis by selecting embryos, produced by super ovulation or in vitro fertilization, prior to implantation, which allows the transfer of embryos with the highest predicted genetic value into recipient cows.

The aim of the study described in this paper was to analyze the expected genetic gain for age at first calving in Nellore cattle using different strategies for incorporating marker assisted embryo pre-selection into breeding schemes. The effects of the proportion of additive genetic variance explained by the QTL and the degree of preselection among embryos were studied.

\section{Methods}

\section{Genetic and population model}

We deterministically simulated marker assisted selection applied to a multiple ovulation and embryo manipulation in vitro fertilization (MOET-IVF) closed nucleus herd to improve AFC in Nellore Bos indicus cattle for a population with discrete generations. We evaluated two forms of marker assisted selection, single-stage selection (scheme A1, see below) using marker assisted selection at two years of age and two-stage selection (schemes A2, A3 and A4, see below) in which there was marker assisted selection of embryos in the first stage followed by a second-stage marker assisted selection of the animals at two years of age. In both cases we evaluated the AFC-QTL additive genetic variance $\left(\sigma_{A}^{2}\right)$ in the range 0.00 to 0.95 . The QTL information was included in the selection index as a correlated trait. Phenotypes $\left(p_{i}\right)$ were the sum of breeding values $\left(a_{i}\right)$ and environmental values $\left(e_{i}\right)$, i.e. $p_{i}=a_{i}+e_{i}$, where $a_{i}$ and $e_{i}$ were assumed to be independent and normally distributed.

Age at first calving (AFC) was the only breeding goal trait and selection was based on breeding value best linear unbiased prediction, using an multi-trait animal model. Response to selection was predicted deterministically using the pseudo-BLUP selection index (Wray and Hill, 1989). The selection index included information on predicted dam AFC based on age at first ovulation, male scrotal circumference (SCR) and the AFC-QTL. The model assumed that the predicted AFC fully correlated with the actual AFC so that dams effectively had an AFC self-performance record. The $\mathrm{AFC}$ estimated breeding values for sires were based on SCR self-performance and AFC-QTL, sib information (full and half-sibs) on SCR, AFC and AFC-QTL, and full pedigree information. The estimated breeding values for dams were based on self-performance for AFC and AFC-QTL, sib information (full and half-sibs) on SCR, AFC and AFC-QTL, and full pedigree information. The type and amount of information used for each sex is summarized in Table 1. In the basal scheme, 30 sires and 120 dams were selected from each generation out of the 4,800 offspring produced (40 embryos per cow), implying a total selected proportion of 0.0125 for sires and 0.05 for dams. Dams and 
calves were selected when 24 months old and had produced embryos and/or offspring for up to 6 months. No information on QTL was used in the basal scheme.

The effect of QTL information and pre-selection proportions on genetic gain was evaluated using four alternative schemes (Table 2). In scheme A1, sires and dams were selected at 2 years of age using all available information including the AFC-QTL data responsible for 0.00 (basal scheme) to $0.95 \sigma_{A}^{2}$. In schemes A2 and A3 embryos were pre-selected in the first stage based on AFC-QTL and pedigree information, while in second stage at 2 years of age genetic gain was based on the same information as was used in scheme A1. Scheme A2 investigated the effect of a varying degree of pre-selection in which the AFC-QTL data was responsible for $0.1,0.3$ or $0.5 \sigma_{A}^{2}$ and the pre-selected proportion of animals ranged from $0 \%$ to $100 \%$, while scheme A3 studied the effect of a varying proportion of AFC-QTL $\sigma_{A}^{2}$ in which it was responsible for 0.02 to 0.95 $\sigma_{A}^{2}$ and the pre-selected proportion of animals was fixed at $32.5 \%$. Scheme A4 had a constant number 800 transferred embryos, considering a constant number of recipient cows, and an increasing number of embryos produced per dam (13 to 2000), the embryos being pre-selected based on AFC-QTL and full pedigree information. The number of selected embryos in the first stage from the total embryos produced and the number of animals selected in the second stage are given in Table 2.

Genetic gain rates were predicted deterministically using the SelAction program (Rutten et al., 2002) employing advanced selection index theory to predict the genetic gain rates of breeding schemes by combining offspring generation phenotypic information with the estimated breeding values of the parent generation to produce an estimated breeding value for the selection candidate (Villa- nueva et al., 1993). Inclusion of estimated breeding values of the parent generation is the reason why pedigree information was included in the models, and allowed prediction of the response to selection using the BLUP-EBV animal model (Wray and Hill, 1989). The program accounts for the reduction of the additive genetic variance due to gameticphase disequilibrium (the Bulmer effect, Bulmer 1971) and for reduction of the selection intensity due to correlated index values of relatives (Meuwissen, 1991).

The genetic and phenotypic parameters used in this work were obtained from the literature (Toelle and Robinson, 1985; Martins-Filho and Lobo, 1992, Ferraz and Eler, 2000, Pereira et al., 2002, Forni and Albuquerque, 2005). It was assumed that $h_{Q T L F C A}^{2}=1$, meaning that the QTL can be identified with certainty, and that the QTL-AFC effect was measured on the same scale as $\mathrm{AFC}$ so that the regression of $\mathrm{AFC}$ on the QTL value equaled one. Therefore, if the AFC-QTL explained a proportion $\rho^{2}$ of the additive genetic variance $\left(\sigma_{A}^{2}\right)$, then the genetic correlation between AFC and the AFC-QTL equaled $\rho$, and the correlation between AFC-QTL and the AFC phenotype equaled $\rho h_{A F C}$, where $h_{A F C}$ is the square root of the AFC heritability. The genetic correlation between the AFC-QTL and scrotal circumference equaled $\rho r_{g}$, where $r_{g}$ is the genetic correlation between AFC and scrotal circumference, Likewise, the phenotypic correlation between scrotal circumference and the AFC-QTL equaled $\rho r_{g} h_{S C R}$, where $h_{S C R}$ is the square root of the scrotal circumference heritability (Table 3 ).

\section{Results and Discussion}

The A1 scheme results are shown in Table 4, which shows the total response results as a percentage of the basal scheme (AFC-QTL effect $=0)$, the response due to selec-

Table 1 - Age at first calving (AFC) quantitative trait loci (QTL), scrotal circumference (SCR) for sires and dams in the two different stages of each scheme.

\begin{tabular}{|c|c|c|c|c|c|c|c|c|}
\hline \multirow[b]{3}{*}{ Source } & \multicolumn{4}{|c|}{ Sires } & \multicolumn{4}{|c|}{ Dams } \\
\hline & \multirow{2}{*}{$\frac{\text { Stage one }}{\text { AFC-QTL }}$} & \multicolumn{3}{|c|}{ Stage two } & \multirow{2}{*}{$\begin{array}{l}\text { Stage one } \\
\text { AFC-QTL }\end{array}$} & \multicolumn{3}{|c|}{ Stage two } \\
\hline & & $\mathrm{AFC}$ & SCR & AFC-QTL & & $\mathrm{AFC}$ & $\mathrm{SCR}^{*}$ & AFC-QTL \\
\hline Self-Performance & Yes & No & Yes & Yes & Yes & Yes & No & Yes \\
\hline Number of half-sibs & No & 60 & 60 & No & No & 60 & 60 & No \\
\hline Number of full-sibs & No & 20 & 19 & No & No & 19 & 20 & No \\
\hline
\end{tabular}

*The SCR for dams refers to the SRC for the sire which serviced the dam.

Table 2 - The number of sires and dams selected in first and second selection stages of each scheme and the number of embryos produced.

\begin{tabular}{|c|c|c|c|c|c|}
\hline \multirow[b]{2}{*}{ Scheme } & \multicolumn{2}{|c|}{ Sires } & \multicolumn{2}{|c|}{ Dams } & \multirow{2}{*}{$\begin{array}{l}\text { Embryos } \\
\text { produced }\end{array}$} \\
\hline & Selected at stage one & Selected at stage two & Selected at stage one & Selected at stage two & \\
\hline A1 & - & 30 & - & 120 & 4800 \\
\hline A2 & 30 to 2400 & 30 & 120 to 2400 & 120 & 4800 \\
\hline A3 & 800 & 30 & 800 & 120 & 4800 \\
\hline A4 & 160 & 30 & 640 & 120 & 1560 to 240000 \\
\hline
\end{tabular}


Table 3 - Heritability (diagonal), phenotypic (upper diagonal) and genetic correlations (lower diagonal) for age at first calving (AFC), scrotal circumference (SCR) and the AFC quantitative trait loci (AFC-QTL).

\begin{tabular}{llll}
\hline & AFC & SCR & AFC-QTL \\
\hline AFC & 0.15 & 0.4 & $0.15 \rho^{*}$ \\
SRC & 0.45 & 0.45 & $0.20 \rho^{\dagger}$ \\
AFC-QTL & $\rho^{* *}$ & ${ }^{3} 0.45 \rho^{\#}$ & 1 \\
\hline
\end{tabular}

*Phenotypic correlation between AFC and AFT-QTL $\left(h_{A F C} \rho=0.15 \rho\right)$.

Phenotypic correlation between SCR and AFC-QTL $\left(r_{g, A F C, S C R} h_{S C R}=0.45\right.$ x $0.45 \rho=0.20 \rho$ ).

**Genetic correlation between AFC and AFC-QTL (square root of the QTL genetic variance).

${ }^{\#}$ Genetic correlation between SCR and AFC-QTL $\left(\mathrm{r}_{\mathrm{g}, \mathrm{AFC}, \mathrm{SCR}} \rho=0.45 \rho\right)$.

tion of dams and sires, the AFC breeding goal standard deviation (AFC STD) and the accuracy for sires and dams for AFC marker assisted selection at two years of age with the AFC-QTL explaining 0.00 to $0.95 \sigma_{A}^{2}$. It can be seen that the reduction of genetic variance due to selection (the Bulmer effect) increased with the proportion of the additive genetic variance explained by the QTL (Table 4). Without marker assisted selection the reduction of genetic variance due to selection was $20 \%$ but rose to $45 \%$ when the AFCQTL explained $95 \%$ of the additive genetic variance, while the AFC additive genetic standard deviation (AFC-STD) decreased from 42 to 35 days. It therefore appears that using AFC-QTL marker assisted selection increased variance reduction due to selection and thus reduced the benefit of using the AFC-QTL. In spite of the reduction in variance, the genetic response increased with the proportion of variance explained by the AFC-QTL. As theoretically expec- ted, increased gain due to increased accuracy was larger than reduction of gain due to reduction of genetic variance (Dekkers and Hospital, 2002). Thus genetic gain with marker assisted selection was superior to the gain achieved in the basal scheme for all values of the proportion of variance explained by the AFC-QTL. Genetic gain for the basal scheme was 49.83 days $(100 \%)$. Using marker assisted selection the response increased from $0.8 \%$ when the AFCQTL explained $0.02 \sigma_{A}^{2}$ up to $55.76 \%$ when the AFC-QTL explained $0.95 \sigma_{A}^{2}$. Accuracy increased from 0.513 to 0.981 for sires and from 0.543 to 0.955 for dams. Accuracy for dams was greater than for sires when there was little or no AFC-QTL effect because the dams had self-performance information for AFC while sires had self-performance information only on the correlated trait of scrotal circumference. As the AFC-QTL effect (i.e. the proportional AFC genetic variation explained by the QTL) increased the dams AFC performance information became less important and the scrotal circumference performance of the sires provided some supplementary information, consequently, the accuracy for sires became slightly higher than that for dams. The benefit of using marker assisted selection was, therefore, larger in regard to the selection of males than females. The genetic superiority of marker assisted selection over the basal scheme was $1.76 \%$ with the AFC-QTL explaining $0.05 \sigma_{A}^{2}$ and $3.80 \%$ when the AFC-QTL explained $0.1 \sigma_{A}^{2}$, similar to the results obtained in other studies (Meuwissen and Goddard, 1996; Spelman and Van Arendonk, 1997).

Scheme A2 used marker assisted selection with embryo pre-selection with varying pre-selection rates. The percentage total response relative to single-stage selection

Table 4 - Scheme A1: Single-stage marker assisted selection. Age at first calving (AFC) quantitative trait locus (QTL) total response (TotResp); response due to selection of dams (RespDam) and sires (RespSire) as a percent of the basal scheme; AFC breeding goal standard deviation (AFC-STD) and the accuracy for sires and dams for single-stage marker assisted selection at two-years of age with the AFC-QTL explaining 0.00 to 0.95 of the additive genetic variance.

\begin{tabular}{|c|c|c|c|c|c|c|}
\hline AFC-QTL Effect & TotResp & Respdam & Respsire & AFC-STD (days) & Sire accuracy & Dam accuracy \\
\hline Basal Scheme* & 100.0 & 100.0 & 100.0 & 41.98 & 0.513 & 0.543 \\
\hline 0.02 & 100.8 & 100.4 & 100.7 & 41.84 & 0.518 & 0.547 \\
\hline 0.05 & 101.8 & 101.3 & 102.2 & 41.79 & 0.525 & 0.552 \\
\hline 0.1 & 103.8 & 102.6 & 104.5 & 41.69 & 0.539 & 0.562 \\
\hline 0.2 & 108.2 & 106.1 & 110.1 & 41.51 & 0.570 & 0.585 \\
\hline 0.3 & 113.7 & 110.0 & 116.5 & 41.07 & 0.607 & 0.614 \\
\hline 0.4 & 119.3 & 114.7 & 123.6 & 40.53 & 0.650 & 0.649 \\
\hline 0.5 & 125.7 & 119.9 & 130.7 & 39.89 & 0.699 & 0.689 \\
\hline 0.6 & 132.1 & 125.5 & 137.8 & 39.14 & 0.752 & 0.736 \\
\hline 0.7 & 138.8 & 131.2 & 145.3 & 38.30 & 0.810 & 0.789 \\
\hline 0.8 & 145.4 & 137.2 & 152.4 & 37.38 & 0.872 & 0.847 \\
\hline 0.9 & 152.2 & 143.7 & 159.6 & 36.37 & 0.943 & 0.916 \\
\hline 0.95 & 155.8 & 147.2 & 163.3 & 35.23 & 0.981 & 0.955 \\
\hline
\end{tabular}

*Using basal scheme (AFC-QTL effect $=0$ ) the total response was 49.83 days and the response due to selection was 23.1 days for dams and 26.7 days for sires. 
after two-stage marker assisted selection with the AFCQTL explaining 0.1, 0.3 and $0.5 \sigma_{A}^{2}$ is shown in Table 5 . During the first stage, embryos were pre-selected based on the AFC-QTL, with the selected proportions ranging from all embryos transferred (100\%) to selection performed fully at the embryo stage. As expected, the genetic gains with marker assisted pre-selection at the embryo stage were lower than the gains achieved with single-stage marker assisted selection. This effect was due to the loss of intensity at two-years old (when more information was available, i.e. self-performance for cows and full and half sibs), resulting in a smaller total selection differential. The greater the proportion of variance explained by the AFC-QTL the higher the selection accuracy and the lower the loss of genetic response due to pre-selection. The results show that it is possible to obtain responses higher than $95 \%$ of the response obtained with single-stage marker assisted selection, when using first-stage selected proportions of $0.4,0.2$ and 0.1 for AFC-QTL substitution effects of $0.1,0.3$ and $0.5 \sigma_{A}^{2}$ respectively. These results suggest that it is possible to reach a satisfactory response by transferring only 10 to $40 \%$ of the collected embryos, thus reducing the total number of recipients without losing genetic gain. Therefore pre-selection at the embryo stage can be useful to reduce cost of the breeding program.

The A3 scheme investigated the response to marker assisted selection at the embryo stage with varying AFCQTL. The total response, response as percentage of the basal scheme, the response due to selection of dams and sires, the AFC breeding goal standard deviation (AFCSTD) and the accuracy for sires and dams after two-stage

Table 5 - Scheme A2: Percentage total response for age at first calving (AFC) two-stage marker assisted selection at the embryo stage (embryo selection rate 0.0125 to 1 ) and at two-years old at additive genetic variance levels of $0.1,0.3$ and 0.5 .

\begin{tabular}{lccc}
\hline & \multicolumn{3}{c}{$\begin{array}{c}\text { Percentage total response for additive genetic } \\
\text { variance levels of } 0.1,0.3 \text { and } 0.5\end{array}$} \\
\cline { 2 - 4 } Pre-selection & 0.1 & 0.3 & 0.5 \\
\hline 0.013 & 43.8 & 67.8 & 83.6 \\
0.1 & 80.2 & 92.1 & 97.6 \\
0.2 & 90.2 & 97.1 & 99.5 \\
0.3 & 95.0 & 98.9 & 99.8 \\
0.4 & 96.5 & 99.5 & 99.9 \\
0.5 & 97.9 & 99.7 & 100.0 \\
0.6 & 98.8 & 99.9 & 100.0 \\
0.7 & 99.4 & 99.9 & 100.0 \\
0.8 & 99.6 & 99.9 & 100.0 \\
0.9 & 99.9 & 100.0 & 100.0 \\
$1.0^{*}$ & 100.0 & 100.0 & 100.0 \\
\hline
\end{tabular}

*At two-years old without pre-selection the total response was 50 days, 55.4 days and 61.7 days for AFC-QTL substitution effect 0.1, 0.3, 0.5 additive genetic variance.
AFC marker assisted selection with the proportions of the additive genetic variance explained by the AFC-QTL ranging from 0 to 0.95 are shown in Table 6. For all the AFC-QTL effects, 40 embryos were generated and 13 transferred so that the pre-selected proportion equaled $32.5 \%$, except for the basal scheme without pre-selection. The genetic gain for the basal scheme was 49.83 days $(100 \%)$. For small proportions of variance explained by AFC-QTL the genetic gains with pre-selection were lower than those achieved in the basal scheme but became higher for AFC-QTL effects larger than $0.2 \sigma_{A}^{2}$. This was caused by reduced accuracy due to embryo pre-selection, which was counteracted by the proportion of variance explained by the AFC-QTL. The situation with the AFC-QTL effect identified as B-13 in Table 6 refers to the situation in which cows produced 13 embryos and no pre-selection was performed at the embryo stage. The production of 3.25 times more embryos (i.e. 40 instead of 13 embryos: the basal scheme vs. B-13) increased genetic gain by approximately $23 \%$. Response improvement was due to increased selection intensity. Even using marker assisted selection with QTL effects explaining a small proportion $(0.02,0.05)$ of the additive genetic variance there was a larger response $(9.0 \%$ and $12.6 \%$, respectively) than that obtained when only 13 embryos were produced. In these situations the greater selection intensity compensated for the pre-selection losses.

Scheme A4 analyzed the response to marker assisted selection at the embryo stage with increased number of embryos. As shown in Table 6, marker assisted pre-selection can be used to reduce the costs related to raising offspring up to 2 years of age as well as maintenance of recipient cows. However, when producing more embryos, marker assisted pre-selection can also be used to increase response to selection compared to the basal scheme. Table 7 presents the percentage total response compared to the scheme with 13 embryos produced per cow for AFC-QTL $0.1,0.3$ and $0.5 \sigma_{A}^{2}$.

As expected, increasing the number of embryos produced and, consequently, first-stage selection intensity, resulted in higher genetic response in the three situations, with a diminishing return when more embryos were produced. The increased genetic response as a consequence of increased selection intensity was higher due to larger QTL effects. For larger QTL effects more embryos could be produced in order to obtain a higher first-stage selection intensity and, consequently, more compensatory responses.

\section{Implications of the study}

Improvement of reproductive techniques such as embryo transfer, in vitro fertilization, in vitro production of oocytes derived from stem cells and cryopreservation has increased the number of embryos produced per cow and, consequently, the number of offspring available for selection. The development of preimplantation genetic diagno- 
Table 6 - Scheme A3: Two-stage marker assisted selection of embryos at stage 1 and two-year old dams and sires at stage 2. Age at first calving (AFC) quantitative trait locus (QTL) total response as a percent of the basal scheme; total response and response due to selection of dams and sires in days; AFC breeding goal standard deviation (AFC-STD) and the accuracy for sires and dams for two-stage marker assisted selection with the AFC-QTL explaining 0.00 to 0.95 of the additive genetic variance.

\begin{tabular}{lccccccc}
\hline \multicolumn{7}{c}{ Equilibrium parameters } \\
$\begin{array}{l}\text { AFC-QTL } \\
\text { effect }\end{array}$ & $\begin{array}{c}\text { Percentage } \\
\text { response }\end{array}$ & $\begin{array}{c}\text { Total response } \\
\text { (days) }\end{array}$ & $\begin{array}{c}\text { Dam response } \\
\text { (days) }\end{array}$ & $\begin{array}{c}\text { Sire response } \\
\text { (days) }\end{array}$ & $\begin{array}{c}\text { AFC-STD } \\
\text { (days) }\end{array}$ & $\begin{array}{c}\text { Sire } \\
\text { accuracy }\end{array}$ & $\begin{array}{c}\text { Dam } \\
\text { accuracy }\end{array}$ \\
\hline Basal scheme* & 100.0 & 49.83 & 23.10 & 26.70 & 41.8 & 0.513 & 0.543 \\
B-13* & 81.04 & 40.37 & 17.40 & 22.97 & 42.0 & 0.518 & 0.547 \\
0.02 & 88.34 & 44.00 & 20.77 & 23.27 & 42.0 & 0.479 & 0.553 \\
0.05 & 91.23 & 45.47 & 21.37 & 24.07 & 41.9 & 0.487 & 0.559 \\
0.1 & 95.32 & 47.50 & 22.27 & 25.20 & 41.7 & 0.501 & 0.568 \\
0.2 & 102.80 & 51.23 & 23.87 & 27.37 & 41.3 & 0.534 & 0.591 \\
0.3 & 109.92 & 54.77 & 25.30 & 29.47 & 40.8 & 0.574 & 0.620 \\
0.4 & 116.71 & 58.13 & 26.63 & 31.50 & 40.1 & 0.618 & 0.654 \\
0.5 & 123.54 & 61.57 & 27.93 & 33.60 & 39.4 & 0.668 & 0.694 \\
0.6 & 131.96 & 65.73 & 29.57 & 36.20 & 38.3 & 0.736 & 0.752 \\
0.7 & 137.14 & 68.33 & 30.57 & 37.77 & 37.6 & 0.781 & 0.792 \\
0.8 & 143.92 & 71.70 & 31.93 & 39.77 & 36.6 & 0.844 & 0.849 \\
0.9 & 151.05 & 75.27 & 33.43 & 41.80 & 35.4 & 0.916 & 0.917 \\
0.95 & 154.70 & 77.07 & 34.23 & 42.83 & 34.8 & 0.955 & 0.955 \\
\hline
\end{tabular}

*The pre-selected proportion with marker assisted selection at the embryo stage was $32.5 \%$ (13 embryos selected and transferred from 40 embryos produced) except in the basal scheme (40 embryos produced per dam) and the B-13 scheme (13 embryos produced per dam) without pre-selection.

Table 7 - Scheme A4: Percentage total response for embryos per cow compared to the scheme in which 13 embryos were produced per cow (100\%, first row) for the age at first calving quantitative trait locus (AFC-QTL) at additive genetic variance levels of $0.1,0.3$ and 0.5 .

\begin{tabular}{lccc}
\hline $\begin{array}{l}\text { Embryos per } \\
\text { cow }\end{array}$ & \multicolumn{3}{c}{$\begin{array}{r}\text { Percentage total response for additive genetic } \\
\text { variance levels of } 0.1,0.3 \text { and } 0.5\end{array}$} \\
\cline { 2 - 4 } & 0.1 & 0.3 & 0.5 \\
\hline $13^{*}$ & 100.0 & 100.0 & 100.0 \\
20 & 106.8 & 109.0 & 109.7 \\
40 & 114.4 & 121.1 & 123.6 \\
100 & 121.0 & 133.9 & 139.5 \\
200 & 124.3 & 142.0 & 150.2 \\
500 & 127.9 & 151.1 & 162.9 \\
1000 & 129.9 & 158.0 & 173.0 \\
2000 & 131.6 & 164.5 & 181.8 \\
\hline
\end{tabular}

*At two-years old without pre-selection the total response was 39.1 days, 44.4 days and 49.7 days for AFC-QTL at additive genetic variance levels of $0.1,0.3$ and 0.5 .

sis allows the pre-selection of embryos using marker information prior to transfer to recipient cows. Embryo pre-selection can be used to either increase genetic response or to reduce costs of the breeding program. The majority of costs in a MOET nucleus breeding program are due to the maintenance of recipient cows and the feeding of the growing animals until selection. Embryo pre-selection using marker assisted selection can substantially reduce the costs by reducing the number of recipient cows and transferred embryos needed. Increased genetic gain could be obtained by increasing the number of embryos produced per cow and pre-selecting those with the desired QTL alleles. This would produce increased total selection intensity and, consequently, higher genetic gain without increasing (or even reducing) the number of recipient cows. The ideal number of embryos produced per cow and consequently the pre-selection rate is dependent on the proportion of the additive genetic variance explained by the QTL, the technical difficulties and the costs involved in producing, evaluating and transferring the embryos, as well as the benefits of implementing these breeding schemes.

These results suggest that marker assisted selection at the embryo stage can be used to enhance genetic response and reduce cost even with markers explaining a relatively small proportion (e.g. 0.05$)$ of the additive genetic variance.

\section{Acknowledgments}

The authors thank the Brazilian agencies CAPES, PRONEX and FAPESP, the Wageningen Institute of Animal Science (WIAS) for financial support and Marc Rutten for providing the software SelAction.

\section{References}

Abdel-Azim G and Freeman AE (2002) Superiority of QTLassisted selection in dairy cattle breeding schemes. J Dairy Sci 85:1869-1880. 
Agca Y, Monson RL, Northey DL, Peschel DE, Schaefer DM and Rutledge JJ (1998) Normal calves from transfer of biopsied, sexed and vitrified IVP bovine embryos. Theriogenology 50:129-145.

Barendse W, Vaiman D and Kemp SJ (1997) A medium-density genetic linkage map of the bovine genome. Mammalian $\mathrm{Ge}-$ nome 8:21-28.

Basrur PK and King WA (2005) Genetics then and now: Breeding the best and biotechnology. Rev Sci Tech 24:31-49.

Bishop MD, Kappes SM, Keele JW, Stone RT, Sunden SL, Hawkins GA, Toldo SS, et al. (1994) A genetic linkage map for cattle. Genetics 136:619-639.

Brascamp EW, Van Arendonk JAM and Groen EAF (1993) Economic appraisal of the utilization of genetic markers in dairy cattle breeding. J Dairy Sci 76:1204-1214.

Bredbacka P (2001) Progress on methods of gene detection in preimplantation embryos. Theriogenology 55:23-34.

Bulmer PM (1971) The effect of selection on genetic variability. Am Naturalist 165:201-211.

Casas E, Lunstra DD and Stone RT (2004) Quantitative trait loci for male reproductive traits in beef cattle. Anim Genet 35:451-453.

Chen SH, Vaught TD, Monahan JA, Boone J, Emslie E, Jobst PM, Lamborn AE, Schnieke A, Robertson L, Colman A, et al. (2002) Efficient production of transgenic cloned calves using preimplantation screening. Biol Reprod. 67:1488-1492.

Chrenek P, Boulanger L, Heyman Y, Uhrin P, Laurincik J, Bulla J and Renard JP (2001) Sexing and multiple genotype analysis from a single cell of bovine embryo. Theriogenology 5:1071-1081.

Dekkers JCM and Hospital F (2002) The use of molecular genetics in the improvement of agricultural populations. Genetics 3:22-32.

Ferraz JBS and Eler JP (2000) Sumário de Touros Nelore 2000. Agropecuária CFM, São José do Rio Preto, 60 pp.

Forni S and Albuquerque LG (2005) Estimates of genetic correlations between days to calving and reproductive and weight traits in Nelore cattle. J Anim Sci 83:1511-1515.

Frazier EL, Sprott LR, Sanders JO, Dahm PF, Crouch JR and Turner JW (1999) Sire marbling score expected progeny difference and weaning weight maternal expected progeny difference associations with age at first calving and calving interval in Angus beef cattle. J Anim Sci 77:1322-1328.

Garcia JF (2001) Practical considerations of embryo manipulation: Preimplantation genetic typing. Theriogenology 56:1393-1399.

Georges M and Massey JM (1991) Velogenetics, or the synergistic use of marker assisted selection and germ-line manipulation. Theriogenology 35:151-159.

Gomez-Raya L and Klemetsdal G (1999) Two-stage selection strategies utilizing marker-quantitative trait locus information and individual performance. J Anim Sci 77:2008-2018.

Gonda MG, Arias JA, Shook GE and Kirkpatrick BW (2004) Identification of an ovulation rate QTL in cattle on BTA14 using selective DNA pooling and interval mapping. Anim Genet 35:298-304.

Haley CS and Visscher PM (1998) Strategies to utilize marker quantitative trait loci associations. J Dairy Sci 81:85-97.

Hansen PJ and Block J (2004) Towards an embryocentric world: The current and potential uses of embryo technologies in dairy production. Reprod Fertil Dev 16:1-14.
Hirayama H, Kageyama S, Moriyasu S, Sawai K, Onoe S, Takahashi Y, Katagiri S, Toen K, Watanabe K, Notomi T, et al. (2004) Rapid sexing of bovine preimplantation embryos using loop-mediated isothermal amplification. Theriogenology 62:887-896.

Kageyama S, Hirayama H, Moriyasu S, Inaba M, Ito D, Ohta H, Sawai K, Minamihashi A and Onoe S (2006) Genetic diagnosis of band 3 deficiency and sexing in bovine preimplantation embryos. J Vet Med Sci. 68:319-323.

Lande R and Thompson R (1990) Efficiency of marker assisted selection in the improvement of quantitative traits. Genetics 124:743-776

Lee JH, Park JH, Lee SH, Park CS and Jin DI (2004) Sexing using single blastomere derived from IVF bovine embryos by fluorescence in situ hybridization (FISH). Theriogenology 62:1452-1458.

Lopes RF, Forell F, Oliveira AT and Rodrigues JL (2001) Splitting and biopsy for bovine embryo sexing under field conditions. Theriogenology 56:1383-1392.

Mackinnon MJ and Georges M (1998) Marker assisted pre-selection of young dairy bulls to progeny testing. Livestock Prod Sci 54:229-250.

Mapletoft RJ and Hasler JF (2005) Assisted reproductive technologies in cattle: A review. Rev Sci Tech 24:393-403.

Martins Filho R, Lobo RB and Oliveira SMP (1992) Idade ao primeiro parto e intervalo entre partos em rebanhos bovinos da raça Nelore. In: Anais da Reunião Anual da Sociedade Brasileira de Zootecnia. Sociedade Brasileira de Zootecnia, Maringá, pp 175.

Meuwissen THE (1991) Expectation and variance of genetic gain in open and closed nucleus and progeny testing schemes. Anim Prod 53:133-141.

Meuwissen THE and Goddard ME (1996) The use of haplotypes in animal breeding schemes. Gen Sel Evol 28:161-176.

Meuwissen THE and Van Arendonk JAM (1992) Potential improvements in rate of genetic gain from marker-assisted selection in dairy cattle breeding schemes. J Dairy Sci 75:1651-1659.

Meuwissen THE, Hayes BJ and Goddard ME (2001) Prediction of total genetic value using genome-wide dense marker maps. genetics 157:1819-1829.

Mizoguchi Y, Watanabe T, Fujinaka K, Iwamoto E and Sugimoto Y (2006) Mapping of quantitative trait loci for carcass traits in a Japanese Black (Wagyu) cattle population. Anim Genet 37:51-54.

Nogueira GP (2004) Puberty in South American Bos indicus (Zebu) cattle. Anim Reprod Sci 83:361-372.

Park JH, Lee JH, Choi KM, Joung SY, Kim JY, Chung GM, Jin DI and Im KS (2001) Rapid sexing of preimplantation bovine embryo using consecutive and multiplex polymerase chain reaction (PCR) with biopsied single blastomere. Theriogenology 55:1843-1853.

Pereira E, de Oliveira HN, Eler JP, Silva JA and Van Melis MH (2006) Use of survival analysis as a tool for the genetic improvement of age at first calving in Nellore cattle. J Anim Breed Genet 123:64-71.

Pereira E, Eler JP and Ferraz JBS (2002) Análise genética de características reprodutivas na raça Nelore. Pesq Agropec Bras 37:703-708.

Powell RL and Norman HD (2006) Major advances in genetic evaluation techniques. J Dairy Sci 89:1337-1348. 
Ruane JEJ and Coleau J (1996) Marker assisted selection for a sex-limited character in a nucleus breeding population. $\mathrm{J}$. Dairy Sci 79:1666-1678.

Rutten MJM, Bijma EP, Woolliams JA and van Arendonk JAM (2002) SelAction: Software to predict selection response and rate of inbreeding in livestock breeding programs. J Hered 93:456-458.

Schnabel RD, Sonstegard TS, Taylor JF and Ashwell MS (2005) Whole-genome scan to detect QTL for milk production, conformation, fertility and functional traits in two US Holstein families. Anim Genet 36:408-416.

Schrooten C and Bovenhuis H (2002) Detection of pleitropic effects of quantitative trait loci in outbreed populations using regression analysis. J Dairy Sci 85:3503-3513.

Schrooten C, Bovenhuis H, van Arendonk JAM and Bijma P (2005) Genetic progress in multistage dairy cattle breeding schemes using genetic markers. J Dairy Sci 88:1569-1581

Schulman NF and Dentine MR (2005) Linkage disequilibrium and selection response in two-stage marker-assisted selection of dairy cattle over several generations. J Anim Genet 122:110-116.

Spelman RJ and Bovenhuis H (1998) Genetic response from marker assisted selection in an outbreed population for differing marker bracket sizes and with two identified quantitative trait loci. Genetics 148:1389-1396.

Spelman RJ and van Arendonk JA (1997) Effect of inaccurate parameter estimates on genetic response to marker-assisted selection in an outbred population. J Dairy Sci 80:3399-3410.

Spelman RL, Garrick DJ and Van Arendonk JAM (1999) Utilization of genetic variance by marker assisted selection in a commercial dairy cow population. Livest Prod Sci 59:51-60.

Spotter A and Distl O (2006) Genetic approaches to the improvement of fertility traits in the pig. Vet J Jan 17; [Epub ahead of print] doi:10.1016/j.tvj1.2005.11.013

Stella A, Lohuis MM, Pagnacco G and Jansen GB (2002) Strategies for continual application of marker-assisted selection in an open nucleus population. J Dairy Sci 85:2358-2367.

Stone RT, Casas E, Smith TP, Keele JW, Harhay G, Bennett GL, Koohmaraie M, Wheeler TL, Shackelford SD and Snelling
WM (2005) Identification of genetic markers for fat deposition and meat tenderness on bovine chromosome 5: Development of a low-density single nucleotide polymorphism map. J Anim Sci 83:2280-2288.

Toelle VD and Robinson OW (1985) Estimates of genetic correlations between testicular measurements and female reproductive traits in cattle. J Anim Sci 60:89-100.

Tominaga K (2004) Cryopreservation and sexing of in vivo- and in vitro-produced bovine embryos for their practical use. $\mathrm{J}$ Reprod Dev. 50:29-38.

Tominaga K and Hamada Y (2004) Efficient production of sex-identified and cryosurvived bovine in vitro produced blastocysts. Theriogenology 61:1181-1191.

Van Der Beek S, Van Arendonk JAM and Groen AF (1995) Power of two and three-generation QTL mapping experiments in an outbreed population containing full-sib or half-sib families. Theor Appl Genetics 91:1115-1124.

Villanueva B, Wray NR and Thompson R (1993) Prediction of asymptotic rates of response from selection on multiple traits using univariate and multivariate best linear unbiased predictors. Anim Production 57:1-13.

Virta J, Markola J, Peippo J, Markkula M and Vilkki J (2002) Sex determination of bovine embryo blastomeres by fluorogenic probes. Theriogenology 57:2229-2236.

Weller JI, Kashi Y and Soller M (1990) Power of "daughter" and "granddaughter" designs for determining linkage between marker loci and quantitative trait loci in dairy cattle. J Dairy Sci 73:252-2537.

Williams JL (2005) The use of marker-assisted selection in animal breeding and biotechnology. Rev Sci Tech 24:379-391.

Wray NR and Hill WG (1989) Asymptotic rates of response from index selection. Anim Production 49:217-227.

Xu S and Muir WM (1991) Multistage selection for genetic gain by orthogonal transformation. Genetics 129:963.

Xu S, Martin TG and Muir WM (1995) Multistage selection for maximum economic return with an application to beef cattle breeding. J Anim Sci 73:699-710.

Associate Editor: Pedro Franklin Barbosa 